\title{
ARTIGO
}

DOI: https://doi.org/10.22481/praxis.v14i29.4108

\section{CONSTITUIÇÃO DA DOCÊNCIA: UMA ANÁLISE A PARTIR O PAPEL DISCURSIVO DO BOLSISTA SUPERVISOR DO PIBID}

\author{
CONSTITUTION OF THE TEACHING PROCESS: AN ANALYSIS FROM THE \\ DISCURSIVE ROLE OF THE SUPERVISOR SCHOLAR
}
CONSTITUCIÓN DE LA DOCENCIA: UN ANÁLISIS A PARTIR DEL PAPEL DISCURSIVO DEL BECADO SUPERVISOR DEL PIBID

\author{
Ester Maria de Figueiredo Souza \\ Universidade Estadual do Sudoeste da Bahia - Brasil
}

Kleber Aparecido da Silva

Universidade de Brasília - Brasil

\begin{abstract}
Resumo: Neste artigo discorre-se sobre a constituição da docência no âmbito do Programa de Bolsa de Iniciação à Docência - PIBID, a partir das práticas mobilizadas pelo bolsista supervisor, docente da educação básica. Busca-se expor as atitudes colaborativas daquele para com o licenciando, bolsista do curso de Letras, acerca de apropriações conceituais sobre o conhecimento da docência. Problematizase a noção de interdisciplinaridade a partir da extração dos discursos instaurados nos encontros formativos do grupo pesquisador e nos indícios das narrativas autorreflexivas escritas pelos sujeitos do estudo. Explora-se os dados com enfoque na abordagem discursiva, a fim de indicar a ação do supervisor na e para a formação do licenciando. Como resultados do estudo, revela-se que ao professor supervisor são impregnadas práticas de modalização da docência que colaboram para a formação do licenciando, aproximando a educação básica do currículo codos cursos de licenciatura.
\end{abstract}

Palavras chave: Docência. Interdisciplinaridade Linguagem.

Abstract: This article discusses the development of teaching skills within the Institutional Scholarship Program for Teaching Initiation (PIBID), from the context of the supervisor scholar, teacher of basic education. The objective is to expose responsive and collaborative attitudes of the supervisor toward the student about their appropriations of concepts on teaching knowledge. We chose the interdisciplinary analysis, by examining this issue in the oral speeches brought in the formative meetings of the research group, and in the evidences of self-reflexive narratives written by the subjects. The data were based on the parallel between concepts, in order to indicate the actions of the supervisor in the formation of the licentiate student. As one of the study results, it was revealed that the supervising teachers are familiar with the organization of teaching practice, which collaborates for the student formation and brings basic education closer to licentiate courses curriculum

Keywords: Teaching. Interdisciplinarity. Language 
Resumen: En este artículo se discurre a acerca de la constitución de la docencia en el ámbito del Programa de Beca de Iniciación a la Docencia - PIBID, a partir de las prácticas movilizadas por el becado supervisor, profesor de la educación básica. Se busca exponer las actitudes colaborativas de aquel hacia el licenciado, becado del Letras, a cerca de apropiaciones conceptuales sobre el conocimiento de la docencia. Se hace una problemática la noción de interdisciplinaridad a partir de la extracción de los discursos instaurados en los encuentros formativos del grupo investigador y en los indicios de las narrativas autorreflexivas escritas por los sujetos del estudio. Se explora los datos con enfoque en el abordaje discursivo, para indicar la acción del supervisor en y para la formación del licenciando. Como resultados del estudio, se revela que al profesor supervisor son impregnadas prácticas de modalización de la docencia que colaboran para la formación del licenciando, aproximando la educación básica del currículo de los cursos de licenciatura.

Palabras-clave: Docencia. Interdisciplinaridad. Lenguaje.

\section{Introdução}

Dadas a natureza e a especificidade deste artigo, tomar-se-á como ponto central o lugar que ocupa a compreensão da interdisciplinaridade nos processos de constituição da docência das bolsistas supervisoras do subprojeto Letras Vernáculas do PIBID-Programa de Bolsas de Iniciação à Docência. Assim, o espaço investigativo que priorizamos para a escrita deste texto é esse lócus formativo do referido Programa, nos seus subprojetos de Letras da Universidade Estadual do Sudoeste da Bahia (UESB) e da Universidade de Brasília (UNB), projetos coordenados pelo autor e autora deste texto.

As agências de formação de professores, como universidades e organismos de governo, pautam a reflexão sobre a interdisciplinaridade como diretriz orientadora para as políticas educacionais de formação docente. Assentaremos a natureza experiencial deste trabalho no âmbito das práticas formativas do PIBID, para pensar a educação como paradigma de formação humana, composições de subjetividades que se irradiam na interação verbal do oficio docente. Na posição discursiva do PIBID, somos coordenador e coordenadora do subprojeto Letras Vernáculas e Letras Português PSBL, respectivamente, que inclui supervisoras, docentes da educação básica e bolsistas, estudantes do terceiro ao sétimo semestre da licenciatura em letras Vernáculas e Letras Modernas. .Como responsáveis pela formação para a docência desse coletivo diverso de sujeitos professores, nos é delegada a responsabilidade de intercalar e articular saberes e práticas entre e com eles sobre iniciação à docência, conhecimento didático da área e interfaces disciplinares e interdisciplinares de planejamento de ensino. 
Essa tríade do PIBID (coordenador da educação superior/supervisor da educação básica/ licenciando) configura-se em um contexto multifacetado de distintas compreensões sobre a docência. Essas compreensões, assumidas por nós como elementos de reflexão sobre a práxis educativa, não raras vezes, indiciam a necessidade de serem desconstruídas e desestabilizadas, para dar vazão às práticas interdisciplinares. Da apresentação desses processos de (des)(re)construção da docência trataremos neste artigo, utilizando de depoimentos de supervisoras e dados dos relatórios dos referidos projetos encaminhados à CAPES.

\section{Os sujeitos do estudo: da natureza dos dados produzidos em (re)análise}

Dentre as distintas tipificações dos bolsistas do PIBID, selecionamos a condição de professor supervisor, como já informamos, como sujeito para este estudo. Ao expor sobre a nossa escolha e viés da constituição dos sujeitos, sentimos a necessidade de pontuar a natureza metateórica de organização e produção de dados para a produção deste texto.

Os dados foram produzidos com base nos depoimentos dos encontros formativos e nas narrativas escritas pelos bolsistas participantes do subprojeto Letras e nos dados dos relatórios de dois projetos integrantes do PIBID em rede nacional: o de Letras Vernáculas da Universidade Estadual do Sudoeste da Bahia, e o de Letras Português/ PBSL da Universidade de Brasília. Tanto o bolsista supervisor, como o bolsista licenciando do curso de Letras produzem gêneros autorias do ensino, como, por exemplo, planos de aula, roteiros e projetos didáticos referentes ao planejamento das atividades e narrativas autorreflexivas do agir docente, como exercício de prática da escrita. Além dessa produção autoral no oral e no escrito, são, ainda, cenários discursivos de produção de dados os encontros formativos realizados na universidade, momentos em que se socializam e complexificam os depoimentos orais acerca de situações de ensino; as problematizações expostas sobre questões de planejamento, de apropriação de professoralidade docente centrada na interdisciplinaridade e o reconhecimento da práxis pedagógica como categoria histórica e cultural, modalizada pelas experiências e subjetividades.

Como dinâmica formativa e de reflexão sobre os percursos da professoralidade, as professoras supervisoras e os licenciandos do curso de Letras assumem gestos autorias de concordância em dispor e autorizar os seus produtos de ensino, os textos autobiográficos e narrativos e depoimentos orais como dados integrantes da pesquisa. Esses produtos são (re) 
tematizados em gêneros discursivos de natureza acadêmica, como relatos de experiências, pôsteres, resumos e artigos técnicos científicos. Extraímos os temas das narrativas em conformidade com a argumentação dos bolsistas. Esses mesmos produtos autorias podem servir a outras provocações investigativas, devido ao teor e as interrelações do campo da docência e formação de professores. Os produtos são parte do banco de dados de um projeto de pesquisa cadastrado na instituição, aprovado pelo comitê de ética e esses são constantemente retomados e ressignificados pelos bolsistas do grupo pesquisador.

A exploração dos temas e significações recorrentes na acepção das supervisoras em dialogia com os licenciandos será retomada com base no estudo de Souza (2008), quando problematiza as condições de trabalho com as práticas discursivas na sala de aula. Souza ( 2008) ao propor a utilização de discursos de práticas pedagógicas como categoria analítica, apresenta um mote organizador para a exploração dos sentidos atribuídos pelos professores aos discursos profissionais e aos seus modos de enunciar:

\begin{abstract}
A instauração dos "discursos de práticas pedagógicas" contribui para a constituição das convenções que o restringem, sendo essa instauração socialmente constitutiva em três aspectos fundamentais: a) as diversas posições de sujeito na aula, b) as diferentes relações sociais e formas de interação, e c) a referenciação dos sistemas de conhecimentos, valores e crenças sobre a realidade. É por meio dessa perspectiva material de compreensão de produção e recepção de discurso que se alicerça a subjetividade inerente às práticas pedagógicas. $\mathrm{O}$ 'eu professor' assume variadas posições e se desdobra em diversos papéis sociais nos processos interacionais com os alunos. (SOUZA, 2008, p.145).
\end{abstract}

Na continuidade dessa argumentação, Vásquez (1997) nos oferece uma reflexão acerca da dimensão subjetiva da práxis pedagógica, focalizando a implicação da relação teoria e prática como dependente do planejamento do processo de ensino. Acrescenta que essa compreensão incorpora, além da subjetividade humana, a dimensão material de realização do trabalho pedagógico e a apropriação de conceitos e técnicas de exploração de realidade.

Talvez, por serem conhecedoras, intuitivamente, da interdependência entre teoria e prática, as professoras supervisoras do PIBID Letras Vernáculas busquem a integração de conteúdos, em um primeiro movimento de não fragmentação do ensino, para se chegar a uma concepção de conhecimento escolar sustentada nas interfaces de saberes, para superar a dicotomia ensino e pesquisa, afirmando que uma concepção interdisciplinar de trabalho pressupõe tomada de posição de abertura para a prática e domínio metodológico para organizar o ensino. 


\section{A interdisciplinaridade e práticas pedagógicas: um nó na formação ou da necessidade de (des)amarrar o nós?}

No âmbito da formação inicial e continuada de professores, a interdisciplinaridade vem sendo reclamada como um elemento importante para que os profissionais da educação entendem o fenômeno educativo na sua totalidade e analisem criticamente o contexto em que estão inseridos. A temática da interdisciplinaridade tem sida tratada tanto no enfoque epistemológico, como construção de conhecimento, como no enfoque pedagógico, tratando da organização didática e metodológica do ensino.A nosso ver, ambos se complementam e impactam na captura do olhar sobre o objeto de ensino.

Fazenda (1979) enfatiza a relevância da ação do professor na tomada de posição nos processos de ensino e aprendizagem na sala de aula, propondo um movimento para o deslocamento da disciplinaridade:

Passa-se de uma relação pedagógica baseada na transmissão do saber de uma disciplina ou matéria, que se estabelece segundo um modelo hierárquico linear, a uma relação pedagógica dialógica na qual a posição de um é a posição de todos. Nesses termos, o professor passa a ser o atuante, o crítico, o animador por excelência. (FAZENDA, 1979, 48)

Dialogando com Paulo Freire (1987), a sua compreensão de interdisciplinaridade valoriza o papel da metodologia de ensino para a construção do conhecimento a partir da relação com o contexto histórico do conhecimento, com a realidade da qual faz parte o sujeito aprendiz. Na sua abordagem dialética, sugere a problematização e desvelamento da realidade ou fenômeno educativo para sistematizar conhecimentos de maneira integradora e não fragmentada. Na sua proposição, vejo que há um convite para que os professores aceitam as múltiplas relações conceituais de conteúdo escolar para organizar o seu trabalho.

Tanto Japiassu (1976), como Fazenda $(1979,1998$, 1994) consideram que a pauta da interdisciplinaridade na educação denuncia a visão fragmentada dos processos de construção do conhecimento escolar, buscando nesse consenso de compreensão revelar a instauração de práticas interdisciplinares que estabelecem rupturas com esse ponto de vista. Essa será sempre uma reação à fragmentação dos objetos e fenômenos sociais, sendo sempre uma busca pelo conhecimento e uma resistência ao conta gotas do ensino por disciplinas.

Em uma releitura das narrativas e dos depoimentos das supervisoras, apresenta-se como uma de suas dificuldades a compreensão da conceituação de interdisciplinaridade na docência, tanto no plano do planejamento de ensino, como na compreensão da realidade 
educacional. Nesse entendimento, orientam o planejamento de ensino com o desenvolvimento de atividades que consideram o papel da linguagem para a aproximação do universo vocabular e cultural com o aluno e a exploração de práticas de ensino de disciplinas especificas, buscando a criação de um ambiente favorável para a aprendizagem.

As reflexões sobre linguagem me levaram a pensar sobre uma questão bem interessante: a readaptação constante e frequente que o professor precisa fazer da sua própria linguagem à do aluno, - a depender da faixa etária deste, da sua condição social, da sua maturidade ou imaturidade, e ainda do seu nível de escolaridade.Em nosso dia a dia convivemos com uma multiplicidade de perfis apresentados pelos nossos alunos, perfis esses que delineiam classes, escolas e, diante dessa pluralidade cultural precisamos estabelecer um "quefazer" pedagógico numa perspectiva discursiva que possibilite ao aluno a compreensão, o entendimento e a interpretação dos fatos levando-os, ainda, a transformá-los. Diariamente, o professor circula por múltiplas classes que apresentam realidades distintas a depender da modalidade de ensino em que esteja atuando, - Ensino Médio, Fundamental e de Jovens e Adultos, por exemplo. Numa linguagem mais livre podemos classificá-lo como professor "camaleão", posto que a cada modalidade em que atua é necessário desvestir-se, adequando-se para que possa, efetivamente, promover um ambiente de ensino-aprendizagem. ... Nesse contexto, atender as especificidades de linguagem e aos interesses de cada grupo convivendo numa mesma classe não é uma tarefa fácil. Este, talvez seja um dos desafios mais frequentes dos professores atualmente: possibilitar a dialogicidade diante da pluralidade que se nos apresenta em nossas classes e escolas. ( UESB. Supervisora Judite, Narrativa 1. Maio 2014)

Quanto ao planejamento e à prática da interdisciplinaridade no ensino, assim se expõe:

Organizei a proposta de interdisciplinaridade com o trabalho com o jornal na sala de aula, para praticar a leitura, interpretação e produção de textos. Cada bolsista sob minha orientação dedicou um tempo para estudar uma parte do jornal e elaborar o plano de aula para aplicar com os alunos, assim os alunos conheciam as partes do jornal. Primeiro, disse para eles que tinha que se preocupar em produzir o jornal por partes e só depois exposição na sala de aula. ( UESB. Supervisora Judite, depoimento encontro formativo. Maio, 2014)

A concepção de interdisciplinaridade revelada pela docente inclui a necessidade de integrar conhecimentos na disciplina especifica, mas deixa a desejar quanto às interfaces com outras disciplinas escolares. Essa primeira compreensão de interdisciplinaridade é presente e recorrente para a constituição da docência e indica que os percursos formativos no PIBID Letras Vernáculas assentam-se em uma pedagogia de trabalho possibilitadora do reconhecimento dos limites da disciplinas. Busca-se a promoção de rupturas conceituais para gerar o espaço da ação interdisciplinar no ensino. É preciso, então, mais do que uma atitude 
interdisciplinar, mais do que integração de conteúdos, pois, deve-se levar em conta uma educação do olhar sobre a realidade já vivenciada e construída, para que se interprete etnograficamente o processo de ensino em suas interfaces teóricas e aplicadas com as outras ciências.

Japiassu (1976) aborda que

[...] do ponto de vista integrador, a interdisciplinaridade requer equilíbrio entre amplitude, profundidade e síntese. amplitude assegura uma larga base de conhecimento e informação. A profundidade assegura o requisito disciplinare/ou conhecimento e informação interdisciplinar para a tarefa a ser executada. A síntese assegura o processo integrador. (JAPIASSU, 1976, p.65).

É importante reconhecer que a interdisciplinaridade é uma movência do sujeito em constante formação e aperfeiçoamento de suas práticas sociais, é também o entendimento de que ensinar e aprender é um ato colaborativo, marcado pelo reconhecimento dos distintos papéis de professor e aluno. Essas compreensões favorecem a organização do trabalho pedagógico, o currículo e os processos de ensino.

A escola que conhecemos estrutura-se por meio de disciplinas curriculares. As supervisoras do PIBID identificam a sua filiação institucional com a disciplina que ministram. Essa base de filiação é sentida pelas professoras como um espaço de segurança, um "assento de interdisciplinaridade", um ponto para gerar a prática interdisciplinar. O depoimento de outra professora supervisora, bolsista do PIBID há 28 meses ressalta a centralidade da disciplina na organização do ensino:

Organizo a interdisciplinaridade na minha disciplina, pois a disciplina é onde trabalho os conceitos, o plano... Todo projeto que a escola promove, articulo com os conteúdos da minha disciplina, se não há disciplina não ocorre a interdisciplinaridade entre as áreas. Busco ampliar o conhecimento na minha disciplina com as demais, mas prevalece mais aquilo que domino. (UESB. Supervisora Sandra. Depoimento encontro formativo. Maio 2014).

A compreensão de interdisciplinaridade como integração entre as disciplinas do currículo é um aspecto que provoca reflexões sobre a natureza epistemológica e metodológica das práticas de ensino. Essa impacta nos processos formativos do próprio supervisor e dos licenciandos sob seu acompanhamento. Mesmo não se configurando em uma ação dialética de transformação e integração do conhecimento escolar, transforma os processos de ensino e aprendizagem, modaliza as interações no interior da sala de aula e a dialogia entre os sujeitos do PIBID. Porquanto, corroboramos que intentar ser professor interdisciplinar implica 
constituição de autoria, revisão do caminho percorrido, explicitação dos medos, das resistências, construção coletiva dos objetivos e metas a serem atingidos, o fazer coletivo constantemente reavaliado.

Nas palavras de Japiassu (1976):

\begin{abstract}
Podemos dizer que nos reconhecemos diante de um empreendimento interdisciplinar todas as vezes em que ele conseguir incorporar os resultados de várias especialidades, que tomar de empréstimo a outras disciplinas certos instrumentos e técnicas metodológicos, fazendo uso dos esquemas conceituais e das análises que se encontram nos diversos ramos do saber, a fim de fazê-los integrarem e convergirem, depois de terem sido comparados e julgados. Donde podermos dizer que o papel específico da atividade interdisciplinar consiste, primordialmente, em lançar uma ponte para ligar as fronteiras que haviam sido estabelecidas anteriormente entre as disciplinas com o objetivo preciso de assegurar a cada uma seu caráter propriamente positivo, segundo modos particulares e com resultados específicos. (JAPIASSU,1976, p. 75)
\end{abstract}

Os bolsistas do PIBID, tanto em formação inicial como continuada, assumem o horizonte da interdisciplinaridade como ambiente para recontextualizações de saberes e nesse entendimento revisam os equívocos de que uma disciplina por si só é um campo interdisciplinar.

A interdisciplinaridade não pode se resumir à natureza do ensino da disciplina, pois é demandante de reelaboração de conceitos do universo da escola. Um dos gestos profissionais que as supervisoras lançam mão é o de orientação para que os licenciandos vivenciem a prática interdisciplinar por meio da integração de projetos didáticos com outras disciplinas escolares, apresentando um produto final do trabalho colaborativo. Essa orientação busca a integração, é uma ação definida para gerar um objeto de avaliação escolar para disciplinas do currículo, como exemplificado no depoimento da supervisora.

\title{
O que (des)aponta dos discursos das supervisoras
}

Como professores e professoras é na escola, em particular, na sala de aula que assumimos performaticamente a ação de ensinar: selecionamos conteúdos, assumimos posições ideológicas, expressamos culturas e exercemos nossa profissão com gestos de professoralidade que são por nós apropriados em espaços formativos diversos. Estamos imersos em uma cultura escolar disciplinar, contudo, clamamos por práticas interdisciplinares, heterogêneas e hibridas para a organização do ensino. 
As supervisoras do PIBID Letras Vernáculas indicam essa contradição como própria da escola, bem como expressam a intuitiva representação de que o conhecimento escolar sedimenta-se, de forma paradigmática em disciplinas. Expõem, também, que a interdisciplinaridade, em seu reverso, é uma reação à abordagem disciplinar e normalizadora do ensino.

Os perfis de bolsistas do PIBID constituem-se em pares opositivos dialógicos e essa dinâmica discursiva é estrato para a apropriação do conhecimento didático sobre a docência e posturas de professoralidade do licenciando. A ação pedagógica dessas trocas cotidianas, na escola de educação básica, na sala de aula e na universidade é lócus de investigação, propiciadora de reflexões para a apropriação do conhecimento sobre a docência e sobre a profissão professor. Nas interações verbaisos pares opositivos constroem-se identitariamente, enquanto sujeitos escolares que se (re)definem pela apropriação do jogo de papéis discursivo de professor licenciado e professor em formação inicial. É o que pode ser revelado no registro do relatório, no depoimento da supervisora

Em outras palavras, o contato regular com os/as alunos/as contribuiu para que pudéssemos observar as carências e limitações desses/as jovens. Em relação ao campo de atuação, as atividades propostas tiveram como objetivo aprimorar as produções textuais dos/as alunos/as. O contato regular em sala de aula nos mostrou a grande necessidade de lidarmos com diferentes estratégias para que consigamos atingir o maior número possível de aprendizes. É um processo complexo, que exige engajamento e coragem para fazer a diferença em um espaço tão complexo. (UNB. Supervisora Ana, PIBIB UNB, 2014).

Nesse entendimento, afirmamos, no âmbito de nossa análise e reflexão, que as supervisoras expõem as possibilidades de apropriação de uma prática interdisciplinar a ser incorporada na sua práxis pedagógica em dois movimentos dialógicos: um de negação e de descrença de realizá-la nas condições materiais que a escola oferece; e outro plenamente realizável no âmbito do agir docente. Nessa ambiguidade, extraímos certa insegurança das supervisoras quanto às possibilidades da escola se efetivar como espaço interdisciplinar, contudo, aparece o microcosmo da sala de aula, da aula especificamente, espaço de acontecimento discursivo e de rupturas conceituais.

No trabalho rotineiro, observamos que a atenção dada aos/às alunos/as fez a grande diferença. Ao longo das atividades, vimos um avanço progressivo. Mesmo aqueles/as que não tiveram um envolvimento efetivo, confidenciaram que, de alguma forma, as atividades desenvolvidas fizeram com que mudassem sua percepção em relação à disciplina e à importância da leitura na vida social. 
Contudo, o maior impacto foi em cada um/a de nós. Neste ano, progredimos e aprendemos muito. Vivenciamos algumas realidades difíceis que envolvem o ensino público. Entretanto, tal experiência nos fez ver que, mesmo sendo uma ação complexa, é possível melhorarmos o nosso ensino e lutarmos pela qualidade que, mesmo em meio às intempéries, pode existir. (UNB. Supervisora Edília, Relatório PIBID UNB, 2014)

Ao longo dos dois anos (2010/2012) de percursos de formação, as supervisoras compreendem a docência como um constructo social baseado em uma confluência de múltiplos saberes e atribuições específicas, o que implica numa formação que a configure como uma profissionalidade com características distintas. È o que se ratifica no depoimento a seguir:

Pensando nisso, propomos, a partir das ações, um ensino de língua que fosse além do mero ensino tradicional, pois a língua deve ser reconhecida em suas mais diversas funções e usos. Dessa forma, a oficina de leitura e produção de texto, a monitoria em Língua Portuguesa aplicada ao texto, o concurso literário, a saída de campo e o cinema na escola têm uma grande relevância para o processo de ensino e aprendizagem, uma vez que impactam em um ensino que ultrapassa as paredes da sala de aula e os muros da escola. Entendemos, nesse processo de formação, que um conhecimento teórico não é suficiente quando trabalhamos em grupo; é preciso, antes, uma boa relação no grupo e uma boa comunicação entre nós e o nosso supervisor e coordenador. Sendo assim, nos organizamos de tal forma que fizemos planejamentos de cada aula das oficinas realizadas e das aulas que foram dadas em sala, em uma oportunidade que tivemos para ter um maior contato com os alunos, com o objetivo de que todos ficassem cientes do que estava sendo trabalhado durante as ações. (UNB. Supervisora Silmara. PIBID/UNB, 2014)

Dos depoimentos e narrativas, sintetizamos os aspectos citados para se refletir acerca da constituição da docência na dialogia do par opositivo professor supervisor e licenciando :

a) ampliação da formação sobre a didática de ensino da disciplina e da docência como objeto de pesquisa

b) definição de gêneros de ensino como produtos autorias do professor, para a organização do trabalho pedagógico, como, por exemplo,o plano de aula, projetos didáticos etc.

c) demarcação da especificidade da professoralidade em formação continuada e em formação inicial,

e) a afirmação de que a docência é um produto das interações mobilizadoras na e pela assimetria de papéis discursivos da identidade de ser professor,

f) permutação entre os diferentes autores e atores do PIBID quanto as modalizações da a assimetria de papéis docentes como coconstitutivas da professoralidade da docência como 
produto do trabalho da interação entre formadores e seus formandos em suas práticas cotidianas.

Em uma narrativa produzida para situar o nosso envolvimento com a tríade Coordenador - Supervisor da Educação Básica - bolsista ID licenciando, assim sintetizamos nossa imersão foramtiva do PIBID. Transcrevemos excertos, no intuito de =demarcar a ênfase concebida ao longo das ações dos projetos, como ilustração de que essa voz narrativa, assim reverbere em outros projetos.

Atraía-me o espaço formativo de encontro com sujeitos que se filiavam a docência em três papéis discursivos distintos: o licenciando, estudante do curso de Letras Vernáculas, o professor egresso, docentes da Educação básica da disciplina Língua Portuguesa e Literatura Brasileira, e meu próprio trabalho como professora formadora e coordenadora do sub projeto na educação Superior, como professora de Metodologias de ensino e Estágio Supervisionado em Letras. Acresce-se a esse conjunto de sujeitos, a situação de que eu estava participando de um mesmo tempo e espaço de uma rede de formação para a docência que me colocava na posição de, no momento presente, estar em sala de aula com os licenciandos, bolsistas ID do PIBID, e com as bolsistas supervisoras, professoras da educação básica, então exalunos do próprio curso de Letras na década de 1990, e , posteriormente, orientandos de pós-graduação/Mestrado.

Essa situação de encontro de distintos sujeitos que se filiam à cultura escolar em espaços distintos (a universidade e a escola básica) me mobilizou, como coordenadora, a encontrar um ponto de convergência que revelasse a docência como a unidade da formação - o que já era o propósito do Programa.

Inicialmente, a representação da docência pelos ID era de prática de ensino. Para meu estranhamento, também para as bolsistas supervisoras. Encontrava-se, assim, um tema para problematizar a formação.

Quais as representações da docência? Como mobilizar processos de (re)construção da docência de sujeitos professores/as que se encontravam em estágios formativos e locus de aprendizagem diversos de exercício da própria docência? Além dessas duas questões de entrada, o planejamento de ensino da língua alvo: aulas de português.

A primeira entrada era revelar as experiências e teorizar essa noção. Assim, o pensamento de Larrosa foi mobilizador para que, afetivamente, os bolsistas expusessem o que lhes afetavam. A memória dos ID expressavam os encontros com as experiências positivas. A memória dos supervisoras, o encontroo com as experiências negativas. Era comum, nos depoimentos dos licenciandos remissões à professora que mais "gostou", ao projeto desenvolvido "fora da sala de aula pelo professor x" ... A memória das supervisoras revelava as dificuldades de "dominar" a classe/turma para manter a atenção dos alunos.( SOUZA, Narrativa. 2017)

Indubitavelmente, o contato periódico que o PIBID favorece aos licenciandos e licenciadas com realidades distintas, via de regra, desconhecidas até então, ou conhecidas 
como cenários da experiência compartilhada na voz do professor, leva ao enfrentamento dos desafios para constituição da docência, para a formação do professor. Esse contato nos primeiros semestres do curso desconstrói se constitui em um elemento estimulador para refletir e decidir sobre a carreira profissional.

\section{Conclusões}

O PIBID ajuda a ter uma perspectiva nova em relação à educação. Estar na sala de aula vivenciando o dia a dia é muito importante para a formação de novos professores, porque eles podem entrar em contato com a realidade da escola e a participação do professor supervisor para a troca de experiências e apropriação de elementos de professoralidade é fator relevante para a constituição da docência..

Muito importante também é a oportunidade de conhecer a realidade na comunidade escolar para que se tenha uma vivência etnográfica do que é a carreira de professor. $\mathrm{O}$ deslocamento de estar na sala de aula, que é antecipado pela própria dinâmica do PIBID e é revelado como um dos estranhamentos pelos bolsistas, é o que possibilita ao professor e professora em formação inicial um deslocamento de suas crenças para, a partir da interpretação dessa realidade, compreender que precisará estar sempre pesquisando novas metodologias e revisando atitudes da docência para instaurar atitudes dialógicas na sala de aula.

Ao bolsista supervisor do PIBID é outorgado o papel de dinamizar o currículo do curso de licenciatura, vez que é um elo na tríade formativa ente a educação básica e a universidade. Ao assumir o papel de coresponsabilidade na e para a formação do licenciando, o PIBID espelha e exemplifica a natureza do ensino que acontece nas escolas da educação básica. Para, o professor é um profissional que carrega uma visão integradora do ensino e professa a busca da interdisciplinaridade para responder aos desafios de problematizar a realidade e sistematizar os conhecimentos de forma integradora.As interações entre supervisor e licenciandos provocam a análise de situações de ensino e problematizam as relações interpessoais: O que você faria em meu lugar? É um enunciado que se expressa nas interlocuções desse para opositivo e sinaliza para uma tomada de posição reflexiva e autorreflexiva das aprendizagens da docência.

Políticas como o PIBID são importantes sob a perspectiva de incluir o debate sobre a interdisciplinaridade como objeto de pesquisa para o ensino das licenciaturas específicas, 
como na constituição da docência. Destaca-se que uma educação continuada, como se instala no âmbito do PIBID, fornece condição para que os bolsistas tenham maior autonomia para perspectivar contextos de sua autoformação e da formação de seu par opositivo; o licenciando. Como fruto de pesquisa, este texto apresenta limitações e recorte de análise, contudo, busca reafirmar a crença de que a formação compartilhada entre pares amplia e gera novos conhecimentos e horizontes de aprendizagens.

\section{REFERÊNCIAS}

FAZENDA, Ivani Catarina. Integração e interdisciplinaridade no ensino brasileiro: efetividade ou ideologia. São Paulo: Loyola, 1979.

FAZENDA, Ivani Catarina Arantes. Didática e interdisciplinaridade. São Paulo : Papirus. 1998

Fazenda, Ivani Catarina Arantes. Interdisciplinaridade: história, teoria e pesquisa. São Paulo: Papirus. 1994

FREIRE, Paulo. Pedagogia do oprimido. Rio de Janeiro: Paz e Terra, 1987.

JAPIASSU, Hilton. Interdisciplinaridade e patologia do saber. São Paulo: Imago. 1976.

SOUZA, Currículos e discursos de práticas pedagógicas. In: Nunes, C. P. ; SANTOS, J. J. R.; CRUSOÉ, N. M. C. Itinerários de pesquisa. Passo Fundo: Editora da Universidade de Passo Fundo. 2008.

SOUZA, Ester Maria de Figueiredo. Narrativa de pesquisa longitudinal PIBID 2012/2017. Universidade Estadual do Sudoeste da Bahia. 2017.

VÁSQUEZ, Adolfo Sánchez. Filosofia da práxis. 2. ed. Rio de Janeiro: Paz e Terra, 1997.

UESB. RELATÓRIO PIBID LETRAS VERNÁCULAS. Universidade Estadual do Sudoeste da Bahia. 2014.

UNB. RELATÓRIO PIBID LETRAS PORTUGUÊS PBSL. Universidade de Brasília, 2014.

\section{SOBRE OS AUTORES:}

\section{Ester Maria de Figueiredo Souza}

Professora Plena da Universidade Estadual do Sudoeste da Bahia (UESB). Doutora em Educação. Pós-doutora em Linguística. Líder do Grupo de Pesquisa Linguagem e Educação GPLED. E-mail: efigueiredo@uesb.edu.br 


\section{Kleber Aparecido da Silva}

Professor Adjunto 4 da Universidade de Brasília (UNB). Doutor em Estudos Linguísticos. Pós-doutor em Linguística Aplicada. Líder do Grupo de Pesquisa Estudos Críticos e Avançados em Linguagem: E-mail: kleberaparecidodasilva@gmail.com 